Rev. Int. Contam. Ambie. 33 (Especial Biotecnología e ingeniería ambiental) 53-61, 2017

DOI: 10.20937/RICA.2017.33.esp01.05

\title{
AISLAMIENTO Y ANÁLISIS CUALITATIVO DE BIOMASA MICROBIANA FÚNGICA DEGRADADORA DE HIDROCARBUROS DE UN CENOTE DE QUINTANA ROO
}

\author{
Ricardo GÓMEZ-REYES ${ }^{1}$, Sergio Alejandro MEDINA-MORENO², \\ Angélica JIMÉNEZ-GONZÁLEZ² y Manuel Alejandro LIZARDI-JIMÉNEZ*
}

${ }^{1}$ Centro de Investigación Científica y de Educación Superior de Ensenada. Carretera Ensenada-Tijuana, número 3918, Zona Playitas, Ensenada, Baja California, México, C. P. 22860

${ }^{2}$ Universidad Politécnica de Pachuca. Carretera Pachuca-Ciudad Sahagún, kilómetro 20, Ex-Hacienda de Santa Bárbara, Zempoala, Hidalgo, México, C. P. 43830

${ }^{3}$ Consejo Nacional de Ciencia y Tecnología-Instituto Tecnológico Superior de Tierra Blanca. Avenida Veracruz sin número, esquina Héroes de Puebla, Colonia Pemex, Tierra Blanca, Veracruz, México, C. P. 95180

*Autor para correspondencia: chamarripas@yahoo.com.mx

(Recibido julio 2015; aceptado junio 2016)

Palabras clave: hongos, biorremediación, petróleo, consumo por contacto directo

\section{RESUMEN}

Se cultivó en biorreactores de puente aéreo un consorcio microbiano para estudios ex situ. El consorcio fue obtenido de un cenote contaminado con fenantreno y naftaleno ubicado en la ciudad de Cancún, Quintana Roo, México. En este trabajo se mostró que el consorcio microbiano está también compuesto por hongos con al menos una especie de Cladosporium, además de las bacterias previamente identificadas en trabajos anteriores del grupo de investigación (Pseudomonas, Diplococcus y Enterobacter), por lo que se conforma así un consorcio mixto. Se modeló la cinética de crecimiento de biomasa fúngica utilizando tres modelos: Gompertz, de Von Bertalanffy y logístico para los datos obtenidos por espectrofotometría. Para todos los casos, Von Bertalanffy fue el modelo que se ajustó de manera sobresaliente a los valores experimentales $(\sigma \leq 0.4)$. El análisis por estereomicroscopía contribuyó a dar una explicación cualitativa de los mecanismos de asimilación de hidrocarburo en biomasa fúngica, al hacer evidente el contacto directo entre esta biomasa fúngica y el hidrocarburo. Finalmente, cultivos en cajas petri recubiertas con petróleo crudo maya corroboraron que la biomasa fúngica obtenida, produce alguna clase de hidrofobinas que permiten romper la tensión superficial entre la interfase hidrofílica/hidrofóbica, favoreciendo así el contacto con el sustrato y los microorganismos.

Key words: fungus, bioremediation, petroleum, direct contact uptake

\begin{abstract}
Microbial consortium has been cultured in airlift bioreactors for ex situ studies. Consortium was obtained in Cancun city from a naphthalene and phenanthrene polluted sinkhole. This work showed that the microbial consortium is further comprised of at least one species fungi (Cladosporium) additionally to bacteria identified in a previous work from our research group (Pseudomonas, Diplococcus and Enterobacter), forming thus a mixed consortium. Mathematical models were used to adjust biomass
\end{abstract}


fungal growth (Gompertz model, de Von Bertalanffy model and logistic model) by using spectrophotometry data. The Von Bertalanffy model fitted with the experimental data $(\sigma \leq 0.4)$. As well as stereomicroscopy analysis gives a qualitative answer for the hydrocarbon uptake mechanism in the fungal biomass. In addition, drop collapsed tests reveal that fungal biomass probably produces some kind of hydrophobins to break the surface tension between the hydrophilic / hydrophobic interface, thus favouring contact between substrate and microorganisms.

\section{INTRODUCCIÓN}

El Estado de Quintana Roo es visitado anualmente por miles de personas que arriban al sur de México y que dejaron una derrama económica anual mayor a $\$ 5000.00$ millones de dólares (MDD) entre los años 2008 a 2014 (SEDETUR 2014). La ciudad de Cancún y la franja de la Riviera Maya son los polos turísticos del estado con mayor desarrollo, infraestructuras hoteleras y por consecuencia con mayor población humana (Medina-Moreno et al. 2014, SEDETUR 2014).

Por otro lado, el Estado de Quintana Roo y la península de Yucatán muestran suelo de origen kárstico de alta porosidad, lo que da origen a la intrusión subterránea de un lente de agua dulce de origen meteorológico que flota sobre una masa de agua marina más densa (Özler 1999, Beddows et al. 2002). Estos lentes subterráneos, comúnmente llamados cenotes, son el único recurso que provee agua dulce a la población humana de Quintana Roo. Sin embargo, sus características naturales están intrínsecamente relacionadas con la contaminación tanto marina como terrestre. Además, el atractivo natural de los cenotes como potencial nicho para el desarrollo turístico y la expansión demográfica de las poblaciones humanas suman diversos factores antrópicos que deterioran la calidad de este recurso natural. En esta vía, se han cuantificado cenotes contaminados por hidrocarburos alifáticos y aromáticos policíclicos (Medina-Moreno et al. 2014). Ambos grupos de hidrocarburos son contaminantes con alto grado tóxico-oncológico para los seres humanos (Agency for Toxic Substances 1995).

Años atrás se propuso la implementación de microorganismos que poseen la capacidad de utilizar esta pluma contaminante como fuente de carbono (Head y Swannell 1999), siendo la biorremediación una estrategia viable para la subsanar tanto cuerpos de agua como suelos contaminados con hidrocarburos (Chaillan et al. 2004, Moreno et al. 2004). En trabajos previos de nuestro grupo de investigación (LizardiJiménez et al. 2013) se identificaron bacterias degradadoras de diésel (Pseudomonas, Diplococcus y Enterobacter) nativas de un cenote de Cancún contaminado por fenantreno y naftaleno. La promoción del crecimiento y la caracterización parcial de dichas bacterias se hizo a través de biorreactores de puente aéreo. Por otro lado, la información sobre la aplicación de microorganismos fúngicos en la biorremediación de cuerpos de agua, es escasa. Sin embargo, algunos estudios reconocen ventajas en el uso de este tipo de microbiota debido a su rápida adaptación en ambientes contaminados y a su eficiente metabolismo para metales pesados e hidrocarburos (Cerniglia et al. 1985), lo que garantiza la supervivencia del inóculo y efectiviza su acción descontaminante. Además, se ha demostrado que los hongos son buenos productores de enzimas extracelulares capaces de degradar distintos contaminantes aromáticos y recalcitrantes debido a la especificidad de su batería enzimática (Colombo et al. 1996, Rafin et al. 2013).

Los modelos matemáticos de crecimiento son empleados para describir el comportamiento de microorganismos en diferentes condiciones químicas, tales como temperatura o $\mathrm{pH}$ (Zwietering et al. 1990) a través de datos de sólidos suspendidos por peso seco (Lizardi-Jiménez et al. 2013) o unidades formadoras de colonias (Tzintzun-Camacho et al. 2012). Sin embargo, en muchas de las aplicaciones la espectrofotometría es usada como un método directo y sencillo para conocer el comportamiento de un sistema biológico, aunque existen escasos reportes de su ajuste sobre modelos matemáticos en bioprocesos.

El objetivo de este trabajo fue aislar y caracterizar microorganismos fúngicos degradadores de hidrocarburos, que además pertenezcan al mismo consorcio microbiano reportado por Lizardi-Jiménez et al. (2013) a través de biorreactores de columna de burbuja, así como encontrar un modelo matemático que se ajuste a los datos experimentales.

\section{MATERIALES Y MÉTODOS}

Consorcio microbiano y biorreactor "madre". Se adquirió un ejemplar de la microbiota autóctona de un cenote reportado como contaminado por 
fenantreno y naftaleno, ubicado en Cancún Quintana Roo (Latitud: $21^{\circ} 9^{\prime} 41.13$ ' N y Longitud: $86^{\circ} 52^{\prime}$ 23.77” W). Se tomó una muestra de agua de $0.5 \mathrm{~L}$, entre 1 y $1.5 \mathrm{~m}$ de profundidad, conforme al cumplimiento de la norma NMX-AA-117-SCFI-2001 para determinación de hidrocarburos en agua. El consorcio fue cultivado en biorreactores de puente aéreo (Fig. 1) con 0.9 L de medio mineral básico (MMB) (Kennedy et al. 1975; Cuadro I) y 0.1 L de la muestra del cenote contaminado con hidrocarburos, bajo las siguientes condiciones experimentales: $\mathrm{T}\left({ }^{\circ} \mathrm{C}\right)=28$, aireación constante $=2 \mathrm{VVM} \mathrm{y} \mathrm{pH}=6.5$ constante, ajustado con $\mathrm{HCl} 2.0 \mathrm{~N}$, más la adición de $13 \mathrm{~g} / \mathrm{L}$ de diésel como única fuente de carbono. Este biorreactor fue realimentado en nuevos lotes secuenciales de 14 días tomando un $10 \%$ en volumen del biorreactor para alimentar los nuevos lotes operacionales.

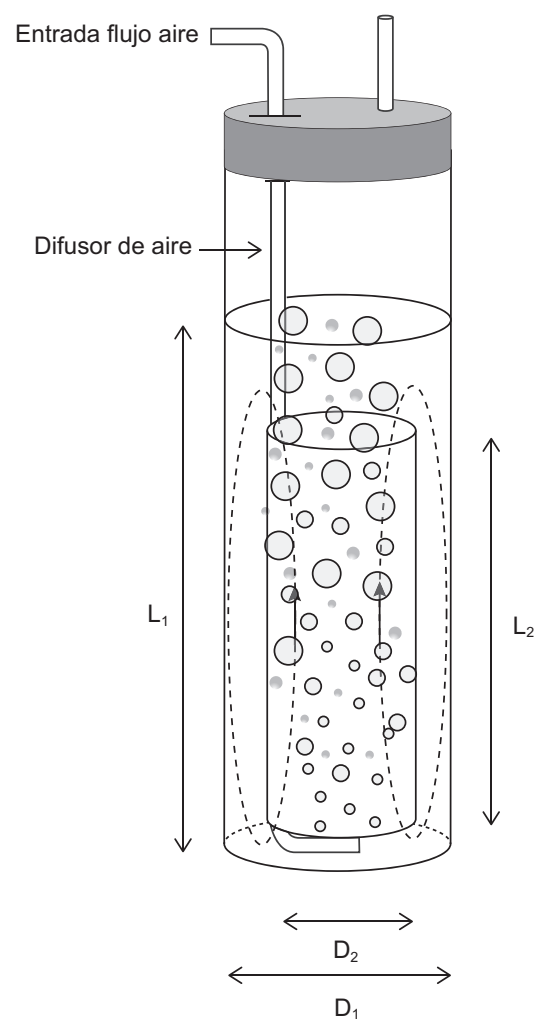

$\mathrm{D}_{1}$ : Diámetro interno reactor airlift

$\mathrm{D}_{2}$ : Diámetro interno tubo concéntrico

$\mathrm{L}_{1}$ : Altura del medio aireado

$\mathrm{L}_{2}$ : Longitud del tubo concéntrico

- Gotas diésel

Burbujas de aire

Fig. 1. Diseño de un biorreactor tipo puente aéreo para el crecimiento de biomasa nativa de cenotes
CUADRO I. TIPOS DE MEDIOS MINERALES USADOS PARA CADA ETAPA DEL EXPERIMENTO, MEDIO MINERAL BÁSICO, MEDIO MINERAL DE AISLAMIENTO, MEDIO MINERAL DE CRECIMIENTO

\begin{tabular}{lccc}
\hline & \multicolumn{3}{c}{ Medio mineral usado (g/L) } \\
\cline { 2 - 4 } Reactivo & $\begin{array}{c}\text { Básico } \\
\text { (Kennedy } \\
\text { et al. } 1975)\end{array}$ & $\begin{array}{c}\text { Aislamiento } \\
\text { (Velasco } \\
\text { 2011) }\end{array}$ & $\begin{array}{c}\text { Crecimiento } \\
\text { (Volke }\end{array}$ \\
\hline $\mathrm{NaNO}_{3}$ & 6.75 & 5.1 & 3 \\
$\mathrm{~K}_{2} \mathrm{HPO}_{4}$ & 2.15 & 0.6 & 1 \\
$\mathrm{KCl}_{\mathrm{MgSO}}-7 \mathrm{H}_{2} \mathrm{O}$ & 1.13 & 0.45 & 5 \\
Ex. De levadura & 0.631 & 0.3 & 0.15 \\
Sacarosa & - & 3 & - \\
Cloranfenicol & - & 20 & - \\
\hline
\end{tabular}

Biorreactor semilla de biomasa fúngica. Se tomó una muestra de $40 \mathrm{~mL}$ del biorreactor madre después del primer lote operacional y se centrifugó (Solbat J-600, Solbat equipment) en frío a 13000 rpm durante $30 \mathrm{~min}$ para retirar el volumen de ambas fases (acuosa/oleosa), así como precipitar la biomasa que incluye tres bacterias identificadas previamente (Pseudomonas, Diplococcus y Enterobacter). Posteriormente se diluyó la pastilla de biomasa obtenida en $10 \mathrm{~mL}$ de una solución de agua destilada estéril + cloranfenicol $(500 \mathrm{mg} / \mathrm{L})$ para sembrar por estriado en cajas de Petri (por triplicado) con agar de cultivo papa dextrosa (PDA) de la marca bd- bioxon, así como dextrosa saborau (DSA) de la marca MCD. Ambos medios fueron incubados para un pre-crecimiento durante $120 \mathrm{~h}$ a $30^{\circ} \mathrm{C}$. Los cultivos que presentaron mejor crecimiento radial y de profundidad fueron resembrados bajo las mismas condiciones únicamente en medio PDA, en el que se transfirieron las esporas libres directo con el asa hacia el centro de las nuevas cajas Petri. Finalmente, se seleccionó el cultivo más representativo en las muestras para transferir las esporas a $100 \mathrm{~mL}\left(2 \times 10^{6}\right.$ esporas $\left./ \mathrm{mL}\right)$, de una solución de medio mineral de aislamiento (MMA) (VelascoÁlvarez 2011; Cuadro I). Con lo anterior se generó un biorreactor semilla de biomasa fúngica, bajo condiciones de $\mathrm{pH}=5$ con $\mathrm{NaOH}$ al $2 \mathrm{~N}+6 \mathrm{~mL} / \mathrm{L}$ de una solución de oligoelementos (Cuadro II), $\mathrm{T}\left({ }^{\circ} \mathrm{C}\right)=30 \pm 2$ y una agitación mecánica de $180 \mathrm{rpm}$ en un incubador durante $120 \mathrm{~h}$.

Cultivo de biomasa fúngica en presencia de hidrocarburos. Se extrajo $10 \%$ en volumen del biorreactor semilla para formar un nuevo lote de operación con $300 \mathrm{~mL}$ de medio mineral de crecimiento (MMC) (Volke et al. 2006) $+2 \mathrm{~mL}$ de solución de 
CUADRO II. SOLUCIÓN DE OLIGOELEMENTOS USADO EN EL MEDIO MINERAL AJUSTADO DURANTE EL CRECIMIENTO DE BIOMASA FÚNGICA

\begin{tabular}{ll}
\hline \multicolumn{2}{c}{ Solución de oligoelementos $(\mathrm{g} / \mathrm{L})$} \\
\hline $\mathrm{FeSO}_{4} * 7 \mathrm{H}_{2} \mathrm{O}$ & 0.1 \\
$\mathrm{CuSO}_{4} * 5 \mathrm{H}_{2} \mathrm{O}$ & 0.015 \\
$\mathrm{ZnSO}_{4} * 7 \mathrm{H}_{2} \mathrm{O}$ & 0.161 \\
$\mathrm{MnSO}_{4} * 7 \mathrm{H}_{2} \mathrm{O}$ & 0.008 \\
\hline
\end{tabular}

oligoelementos (Cuadro II) y como fuente de carbono se utilizaron $13 \mathrm{~g} / \mathrm{L}$ de diésel y crudo maya en lotes independientes cultivados en matraces de 500 $\mathrm{mL}$. Los matraces fueron incubados a $\mathrm{T}\left({ }^{\circ} \mathrm{C}\right)=30 \pm 2$ y agitados continuamente a $180 \mathrm{rpm}$ por $120 \mathrm{~h}$. Una alícuota de cada matraz fue analizada por microscopía (QM-Q8, Quasar) para observar la interacción de la biomasa fúngica en contacto con el diésel y crudo maya en distintos días del crecimiento.

Cinética de crecimiento y modelado matemático. Con un espectrofotómetro (Jasco Jenway- modelo 6405) se midieron las variaciones de absorbancia de la biomasa cultivada en los matraces con medio MMC + diésel cada 24 h durante $5 \mathrm{~d}$ (Cuadro III). Las células de la biomasa se separaron por centrifugación a $4000 \mathrm{x} \mathrm{g} \mathrm{a} 4{ }^{\circ} \mathrm{C}$ durante $10 \mathrm{~min}$, seguido de un lavado con agua desionizada y resuspensión (Rivera-Martínez et al. 2015). Para esta etapa, se efectuó una curva de calibración, en la que se ubicaron los puntos más altos en la absorbancia a $403 \mathrm{~nm}$, mientras que el medio MMC fue usado como blanco

CUADRO III. ABSORBANCIA A 403 nm dURANTE LAS PRIMERAS 120 HORAS DE LOS TRATAMIENTOS EN MEDIO MINERAL DE CRECIMIENTO + DIÉSEL. ENSAYO 1 (E.1), ENSAYO 2 (E.2), ENSAYO 3 (E.3), ENSAYO 4 (E.4). DESVIACIÓN ESTÁNDAR ENTRE ENSAYOS $(\sigma)$. ABSORBANCIA A LA MÁXIMA BIOMASA PRODUCIDA (A). ABSORBANCIA A LA BIOMASA INICIAL $\left(\mathrm{S}_{0}\right)$

\begin{tabular}{lccccc}
\hline \multirow{2}{*}{$\begin{array}{l}\text { Tratamiento } \\
\text { Tiempo (h) }\end{array}$} & E.1 & E.2 & E.3 & E.4 & $\sigma$ \\
\cline { 2 - 6 } & \multicolumn{5}{c}{$403 \mathrm{~nm}$} \\
\hline 0 & 1.35 & 1.40 & 1.39 & 1.32 & 0.04 \\
24 & 1.42 & 1.48 & 1.50 & 1.51 & 0.04 \\
48 & 1.52 & 1.50 & 1.61 & 1.50 & 0.05 \\
72 & 1.45 & 1.53 & 1.48 & 1.52 & 0.04 \\
96 & 1.49 & 1.60 & 1.55 & 1.66 & 0.07 \\
120 & 1.48 & 1.59 & 1.56 & 1.52 & 0.05 \\
$\mathrm{~A}$ & 1.52 & 1.60 & 1.61 & 1.66 & \\
$\mathrm{~S}_{0}$ & 1.35 & 1.40 & 1.39 & 1.32 & \\
\hline
\end{tabular}

para las mediciones. Finalmente, se compararon los datos experimentales obtenidos por espectrofotometría con tres modelos no lineales para la predicción del crecimiento microbiano: Gompertz (Zwietering et al. 1990), Von Bertalanffy (Von Bertalanffy 1957) y el modelo logístico (Ricker 1979). El uso de cloranfenicol, que inhibe la síntesis proteica bacteriana al unirse con la subunidad $50 \mathrm{~S}$ del ribosoma desde el biorreactor semilla, permitió que el crecimiento modelado sólo fuese el de biomasa fúngica.

Evaluación del contacto célula-hidrocarburo. Una solución de medio MMC fue solidificado con agar PDA en cajas Petri, al añadir sobre los medios sólidos una cubierta de $\sim 50 \mu \mathrm{L}$ de diésel y crudo maya en una proporción 1:1 (Morikawa et al. 1992). Se sembró por goteo $0.25 \mathrm{~mL}$ de un inóculo en dilución 1:100 del crecimiento obtenido en el medio MMC y se almacenó el cultivo a $30^{\circ} \mathrm{C}$ durante $72 \mathrm{~h}$.

Análisis estadístico. Se calculó la tendencia logarítmica de la cinética de crecimiento respecto a los modelos, el coeficiente de determinación $\left(\mathrm{R}^{2}\right) \mathrm{y}$ la desviación estándar $(\sigma)$.

\section{RESULTADOS Y DISCUSIÓN}

Los datos experimentales obtenidos durante los ensayos de crecimiento de biomasa en medio MMC + diésel mostraron una tendencia en el crecimiento sigmoide con una desviación estándar entre ensayos menor o igual a 0.07 (Fig. 2). El ensayo E.2 presentó una tendencia logarítmica con una $\mathrm{R}^{2}=0.80$. Por otro lado, los ensayos E.1, E.3 y E.4 decayeron en las últimas $72 \mathrm{~h}$. Se puede atribuir que el decaimiento ocurrió por falta de las formas asimilables del diésel como fuente de carbono para la biomasa en medio MMC, o bien a un proceso de degradación del hidrocarburo. Sin embargo, la predicción mediante el modelamiento matemático permitió corroborar que el promedio de los ensayos se apega a las fases de desarrollo del crecimiento microbiano típico (Larcher et al. 2006) debido a que las curvas obtenidas experimentalmente presentaron coherencia con las curvas calculadas con cualquiera de los modelos (Figura 3) . Von Bertalanffy fue el modelo que mejor se ajustó al promedio de valores experimentales de la cinética microbiana $(\sigma \leq 0.4)$. En la figura 3 puede observarse tanto la fase de crecimiento como la fase estacionaria típica de una cinética microbiana al término del día cinco. Desde esta perspectiva se puede inferir que la biomasa fúngica se adaptó a una fuente de carbono poco asimilable durante los primeros cuatro días de cultivo, lo que dio como resultado la máxima capacidad 


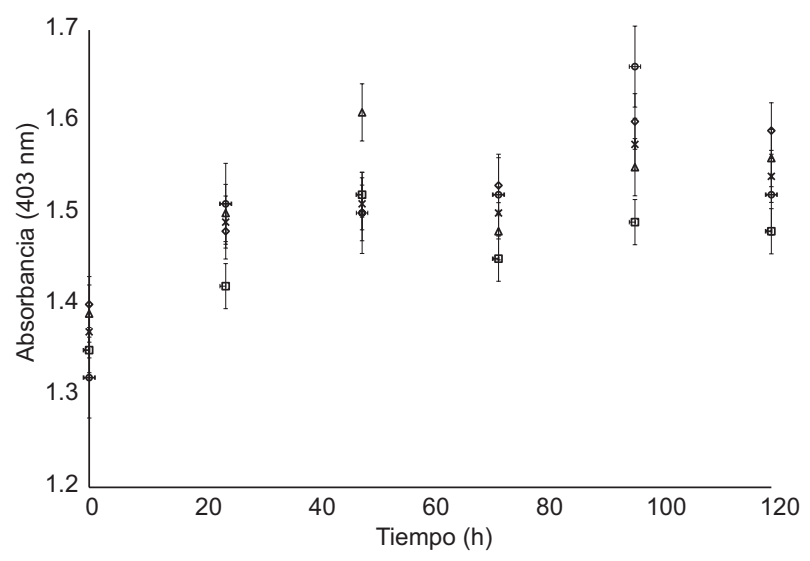

Fig. 2. Cinética de crecimiento microbiano para los ensayos E.1 $(\square)$, E.2 $(\diamond)$, E.3 $(\Delta)$, E.4 (०) y su promedio $(*)$

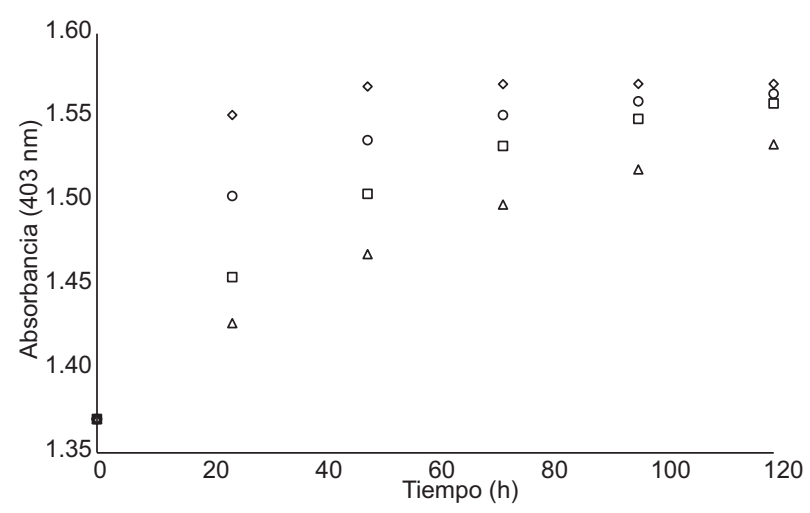

Fig. 3. Predicción de cinética de crecimiento con tres modelos matemáticos; Gompertz ( $\square)$, de Von Bertalanffy $(\Delta)$ y el modelo logístico $(\diamond)$ para justificar que los datos experimentales $(\circ)$ se apegan a las fases de desarrollo durante una cinética de crecimiento dinámica de asimilación del hidrocarburo a $1.6 \mathrm{~nm}$ de absorbancia respecto a su fase estacionaria de cultivo. Aunque los datos experimentales obtenidos por espectrofotometría expresan no sólo el crecimiento de la biomasa fúngica si no otras variables de respuesta, como la degradación parcial de diésel o la producción de otro posible metabolito secundario en los biorreactores, este ensayo fue útil para "reflejar" el crecimiento de la biomasa fúngica a través del uso de modelos matemáticos no lineales diseñados para valorar el crecimiento microbiano fúngico usando directamente los datos de absorbancia. Sin embargo, es imperativo expresar que la concentración inicial de biomasa en el biorreactor fue $0.08 \pm 0.02 \mathrm{~g} / \mathrm{L}$ y la final fue $1.2 \pm 0.02 \mathrm{~g} / \mathrm{L}$ lo cual coincide con el crecimiento que se expresa en los modelos.

El modelo de Von Bertalanffy permitió ajustar los datos experimentales obtenidos por espectrofotometría hacia las fases de desarrollo del crecimiento microbiano fúngico ya que al adicionar cloranfenicol inhibió la síntesis proteica bacteriana.

El análisis a la morfología de la biomasa fúngica sugiere que entre sus constituyentes, el consorcio tiene hongos filamentosos de la especie Cladosporium. En la figura 4 se observan conidios ramificados (ramoconidios) y cadenas de conidios característicos de las hifas de esta especie, además de mostrar un color marrón oliváceo, una capa mucosa y una forma estriada del micelio muy similar a $C$. perangustum (Jang et al. 2013). Las especies de Cladosporium tienen preferencia por el medio de cultivo PDA, en el que alcanzaron un diámetro de crecimiento micelar máximo de $60 \mathrm{~mm}$ (Bensch et al. 2010).

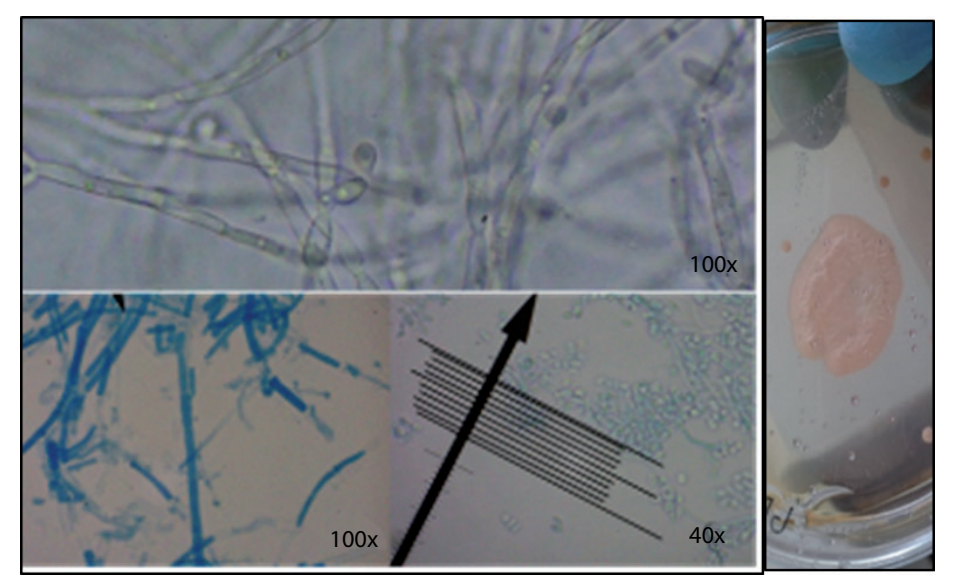

Fig. 4. Análisis morfológico de la biomasa fúngica: Durante todas las observaciones por microscopía se visualizaban hifas tabicadas y septadas que sugieren corresponder al grupo Cladosporium. La flecha negra que aparece en la imagen es un patrón de referencia en el microscopio 
Esto se ve apoyado por nuestros cultivos al tener un crecimiento fructífero y de similar diámetro en medio de cultivo PDA en lugar de DSA. Adicionalmente, Parbery (1971) y Cofone et al. (1973) han reportado la capacidad de Cladosporium para adaptarse a sitios contaminados por hidrocarburos, lo que parece respaldar que las observaciones morfológicas podrían ser las correctas al identificar este hongo como parte de un consorcio microbiano aislado de un cenote contaminado por fenantreno y naftaleno en la ciudad de Cancún.

En los experimentos para evaluar los mecanismos de contacto celular al hidrocarburo, se detectan dos formas diferentes de adaptación al crudo maya: a) halo transparente alrededor del radio de la biomasa y $b$ ) halo oscuro alrededor del radio de la biomasa (Fig. 5). Sneha et al. (2012) asocian el diámetro del halo transparente con la producción de biosurfactantes en bacterias degradadoras de hidrocarburos. Aunque en hongos no existen reportes sobre la producción de biosurfactantes, existe la capacidad de ciertas especies fúngicas para producir proteínas de bajo peso molecular con actividad surfactante llamadas hidrofobinas (Cox y Hooley 2009). Este tipo de adaptación permite la adhesión de las gotas de hidrocarburos, lo que facilita la difusión de los sustratos hidrofóbicos al interior de las células microbianas (Bouchez 2001, Van Hamme 2001, Abbasnezhad 2011, Tzintzun-Camacho et al. 2012).

Cladosporium ha sido ampliamente caracterizado por producir distintos tipos de hidrofobinas durante otros procesos adaptativos (Lacroix et al. 2007), lo que sustentan los hallazgos encontrados en los experimentos para evidenciar el contacto célula-hidrocarburo realizado durante el presente trabajo. Esto último puede interpretarse como el papel que desempeña Cladosporium en el consorcio mixto, en el que facilita la interacción hidrocarburo/ célula durante el proceso de biorremediación. No obstante es imperativo mencionar que una técnica molecular sería ideal para clasificar el hongo encontrado en este trabajo. Las ventajas de emplear cultivos mixtos en lugar de cultivos puros para la degradación de hidrocarburos han sido demostradas (Machin-Ramírez et al. 2010) y los beneficios son atribuidos a los efectos sinérgicos que se establecen entre los diferentes miembros de los consorcios microbianos. En la interacción poblacional que se establece en un consorcio microbiano mixto, es posible que algunas especies remueven $\mathrm{u}$ oxiden parcialmente los metabolitos producidos por otros microorganismos hidrocarbonoclastas (Ghazali 2004, Díaz-Ramírez et al. 2008).

El análisis por microscopía durante el crecimiento de biomasa fúngica en matraces con medio MMC, revela que parte de la biomasa libre se desplaza continuamente hacia gotas aisladas de los hidrocarburos usados (Fig. 6), adhiriéndose entre el contorno de las fracciones apartadas. En trabajos previos (TzintzunCamacho et al. 2012) se muestra que, por lo general, la biomasa microbiana consume los hidrocarburos en pequeñas gotas emulsificadas. Por lo que es importante mantener una agitación constante que mezcle lo más posible la fase oleosa con la acuosa. Por otra parte después de un periodo $<120 \mathrm{~h}$, se logró observar que parte de la biomasa era capaz de penetrar hacia el interior de las gotas de hidrocarburo. Puesto que se trata de una imagen bidimensional no se puede

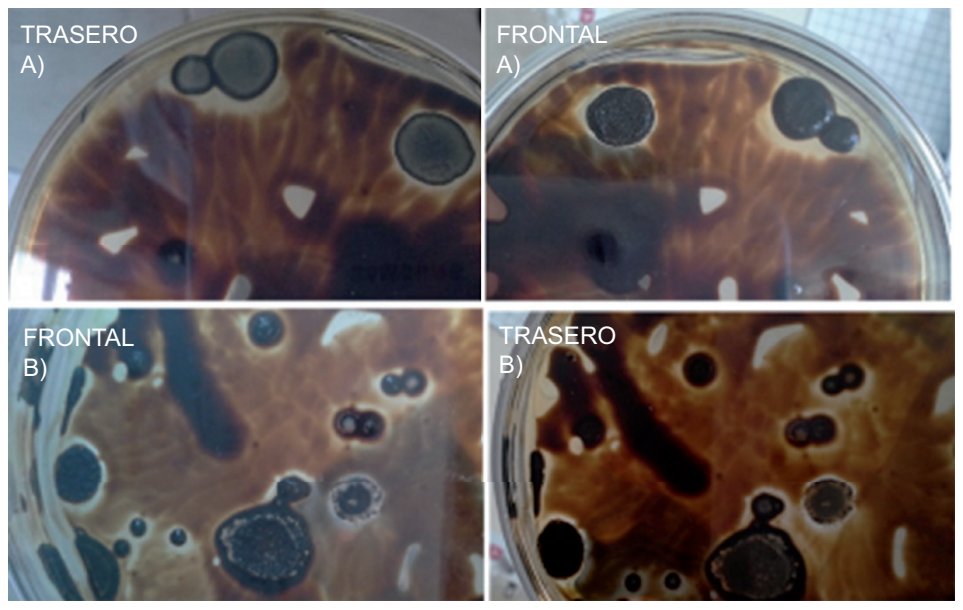

Fig. 5. Pruebas del medio mineral de crecimiento solidificado cubierto con petróleo crudo maya. En el caso A) y B) el petróleo se superpuso en la biomasa fúngica 


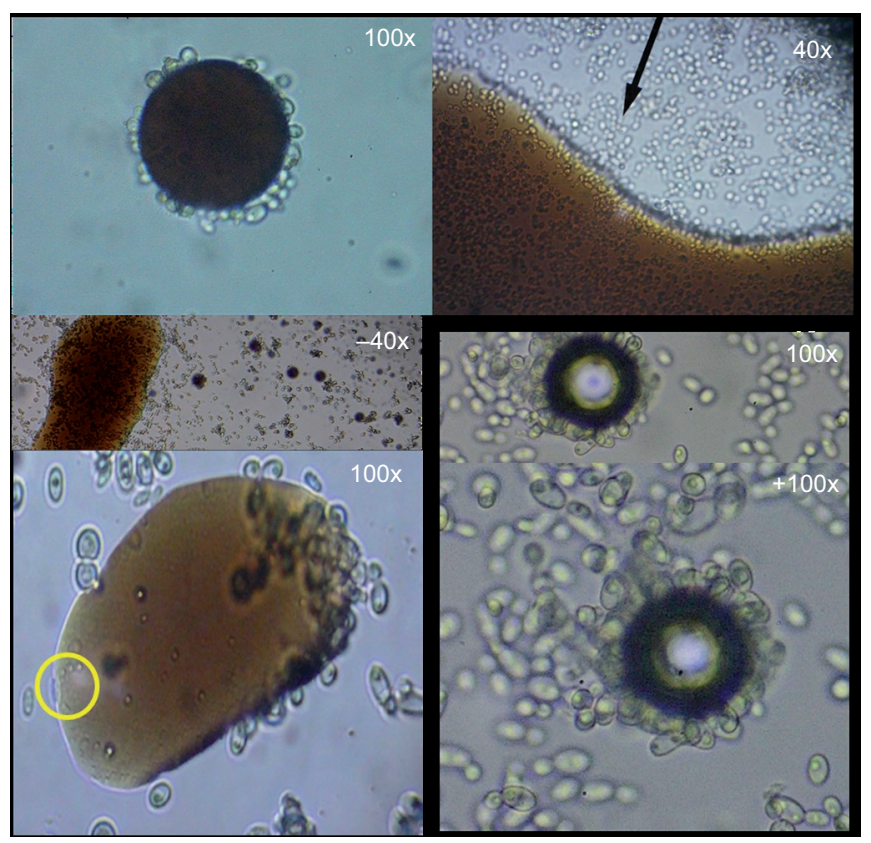

Fig. 6. Microscopía durante el crecimiento de biomasa fúngica en matraces con medio mineral de crecimiento. La biomasa fúngica se adhiere hacia el contorno de una gota aislada de diésel, diversas fracciones de crudo maya son aprovechadas por esporas libres en el sistema. La flecha negra es un patrón de referencia en el microscopio

aseverar que la biomasa esté penetrando directamente en las fracciones de hidrocarburo. No obstante, esta última premisa puede dar significado a la hipótesis acerca de la producción de hidrofobinas en la pared celular de la biomasa fúngica.

\section{CONCLUSIÓN}

El crecimiento fúngico en medio $\mathrm{MMC}+$ diésel demostró que el consorcio hidrocarbonoclasta aislado de un cenote contaminado en Cancún y crecido en un biorreactor está compuesto de un cultivo mixto en el cuál la biomasa fúngica puede ser capaz de degradar diferentes fracciones de los hidrocarburos que fueron utilizados como fuente primaria de carbono. El crecimiento de la biomasa fúngica fue ajustado a modelos matemáticos no lineales diseñados para calcular el crecimiento microbiano, en los que se obtuvieron factores de correlación relevantes. El modelo Von Bertalanffy permitió describir matemáticamente las fases de desarrollo del crecimiento microbiano fúngico. La biomasa fúngica degradadora de hidrocarburos está compuesta por hongos del género Cladosporium, reportado como degradador de hidrocarburos en suelos. Las observaciones microscópicas y las pruebas del medio MMC solidificado recubierto con petróleo crudo maya dan indicios de que la biomasa microbiana fúngica produce proteínas antipáticas, probablemente hidrofobinas.

\section{AGRADECIMIENTOS}

R. Gómez-Reyes agradece a M. A. Lizardi-Jiménez y a la Universidad Politécnica de Pachuca. A los Ingenieros Decle-Carrasco y Tec-Caamal, por el apoyo técnico durante el desarrollo de los experimentos. A la Coordinación Nacional de Becas de Educación Superior en el marco de becas de movilidad nacional (folio 620440) por el apoyo financiero.

\section{REFERENCIAS}

Abbasnezhad H., Gray M. y Foght J. (2011). Influence of adhesion on aerobic biodegradation and bioremediation of liquid hydrocarbons. Appl. Microbiol. Biotechnol. 92, 653-675. DOI: 10.1007/s00253-011-3589-4.

ATSDR (1995). Toxicological profile for Polycyclic Aromatic Hydrocarbons (PAHs). Agency for Toxic Substances and Disease Registry. US Department of 
Health and Human Services, Public Health Service, Atlanta, Georgia, EUA, 587 pp.

Beddows P., Smart P., Whitaker F. y Smith S. (2002). Density stratified groundwater circulation on the Caribbean Coast of Yucatan peninsula, Mexico. Karst Frontiers. Karst Waters Institute Special Publication 7, 129-134.

Bensch K., Groenewald J.Z., Dijksterhuis J., StarinkWillemse M., Andersen B., Summerell B. A., Shin H. D., Dugan F. M., Schroers H. J., Braun U. y Crous P. W. (2010). Species and ecological diversity within the Cladosporium cladosporioides complex (Davidiellaceae, Capnodiales). Stud. Mycol. 67, 1-94.

DOI: 10.3114/sim.2010.67.01

Bertalanffy L. (1957). Quantitative laws in metabolism and growth. Q. Rev. Biol. 32, 217-231.

Bouchez-Naïtali M., Blanchet D., Bardin D. y Vandecasteele J. (2001). Evidence for interfacial uptake in hexadecane degradation by Rhodococcus equi: the importance of cell flocculation. Microbiology 147, 2537-2543. DOI: 10.1099/00221287-147-9-2537

Cerniglia C., White G. y Heflich R. (1985). Fungal metabolism and detoxification of polycyclic aromatic hydrocarbons. Arch. Microbiol. 143, 105-110.

DOI: 10.1007/BF00411031

Chaillan F., Le-Fleche A., Bury E., Phantavong Y. H., Grimont P., Saliot A. y Oudot J. (2004). Identification and biodegradation potential of tropical aerobic hydrocarbon-degrading microorganisms. Res. Microbiol. 155, 587-595.

DOI: $10.1016 /$ S0923-2508(04)00104-4

Cofone L., Walker J. D. y Cooney J.J. (1973). Utilization of Hydrocarbons by Cladosporium resinae. J. Gen. Microbiol. 76, 243-246.

DOI: $10.1099 / 00221287-76-1-243$

Colombo J. C., Cabello M. y Arambarri A.M. (1996). Biodegradation of aliphatic and aromatics hydrocarbons by natural soil microflora and pure cultures of imperfect and lignolitic fungi. Environ. Pollut. 94, 355-362.

DOI: 10.1016/S0269-7491(96)00044-9

Cox P. y Hooley P. (2009). Hydrophobins: New prospect for biotechnology. Fungal Biology Reviews 23, 40-47. DOI: 10.1016/j.fbr.2009.09.001

Díaz-Ramírez I., Escalante Espinosa E., Favela Torres E., Gutiérrez-Rojas M. y Ramírez-Saad H. (2008). Design of bacterial defined mixed for biodegradation of specific crude oil fraction, using population dynamics analysis by DGGE. Int. Biodeter. Biodegr. 22, 21-30. DOI: 10.1016/j.ibiod.2007.11.001

Ghazali F., Abdul Rahman R. y Salleh A. (2004). Biodegradation of hydrocarbons in soil by microbial consortium. Int. Biodeter. Biodegr. 54, 61- 67.

DOI: $10.1016 /$ j.ibiod.2004.02.002
Head I. y Swannell R. (1999). Bioremediation of petroleum hydrocarbon contaminants in marine habitats. Curr. Opin. Biotech. 10, 234-239.

DOI: 10.1016/S0958-1669(99)80041-X

Jang Y., Lee Y. M., Kim G. H. y Kim J. J. (2013). Two species of Cladosporium associated with wood discoloration in Korea. Mycotaxon. 124, 21-29.

DOI: $10.5248 / 124.21$

Kennedy R. S., Finnerty W. R., Sudarsanan K. y Young R. A. (1975). Microbial assimilation of hydrocarbons. Arch. Microbiol. 102, 75-83.

DOI: $10.1007 / \mathrm{BF} 00428349$

Lacroix H., Whiteford J. R. y Spanu Pietro D. (2007). Localization of Cladosporium fulvum hydrophobins reveals a role for Hcf-6 in adhesion. FEMS Microbiol. Lett. 286, 136-14. DOI: 10.1111/j.1574-6968.2008.01227.x

Larcher I. y Cattaneo C. (2006). Simulación de crecimiento de microorganismos utilizando el método monte carlo. Mecánica Computacional 25, 2505-2518.

Lizardi-Jiménez M. A., Leal Bautista R., Ordaz A. y Reyna-Velarde R. (2013). Airlift bioreactor for hydrocarbon water pollution remediation in tourism development pole. Desalin. Water. Treat. 54, 44-49. DOI: $10.1080 / 19443994.2013 .876670$

Machín-Ramírez C., Moralesa D., Martínez-Morales F., Okoh A.I. y Trejo-Hernández M.R. (2010). Benzo[a] pyrene removal by axenic- and co-cultures of some bacterial and fungal strains. Int. Biodeter. Biodegr. 64, 538-544.

DOI: $10.1016 /$ j.ibiod.2010.05.006

Medina-Moreno S. A., Jiménez-González A., GutiérrezRojas M. y Lizardi-Jiménez M. A. (2014). Hydrocarbon pollution in underwater sinkholes as a function of tourism development in the Mexican Caribbean. Rev. Mex. Ing. Quím. 13, 509-516.

Moreno C., González A. y Blanco M. (2004). Tratamientos biológicos de suelos contaminados: contaminación por hidrocarburos. Aplicaciones de los hongos. Rev. Iberoam. Micol. 21, 103-120.

Morikawa M., Hirata Y. y Imanaka T. (1992). Isolation of a new surfactin producer Bacillus pumilusA-1, and cloning and nucleotide sequence of the regulator gene psf-1. J. Ferment. Bioeng. 74, 255-261. DOI: $10.1016 / 0922-338 X(92) 90055-Y$

Özler H. M. (1999). Water balance and water quality in the curuksu basin. Hydrogeol. J. 7, 405-418.

DOI: $10.1007 / \mathrm{s} 100400050212$

Tzintzun-Camacho O., Loera O., Ramírez-Saad H. C. y Gutiérrez-Rojas M. (2012). Comparison of mechanisms of hexadecane uptake among pure and mixed. Int. Biodeter. Biodegr. 70, 1-7. DOI: 10.1016/j.ibiod.2012.01.009 
Parbery (1971). Biological problems in jet aviation fuel and the biology of Amorphotheca resinae. Material und Organismen 6, 161-208

Rafin C., de Foucault B. y Veig E. (2013). Exploring micromycetes biodiversity for screening benzo[a]pyrene degrading potential. Enviorn. Sci. Pollut. Res. 20, 3280-3289 DOI: 10.1007/s11356-012-1255-8

Ricker W. E. (1979) Growth rates and models. Fish Physiol. 8, 677-743.

Rivera-Martínez E., Cárdenas-González J. F., MartínezJuárez V. M. y Acosta-Rodríguez I. (2015). Remoción de cromo (VI) por una cepa de Aspergillus niger resistente a cromato. Inf. Tecnol. 26, 13-20.

DOI: $10.4067 / \mathrm{S} 0718-07642015000400003$

SEDETUR (2014). Indicadores turísticos. Secretaría de Turismo del Estado de Quintana Roo [en línea]. http://sedetur.qroo.gob.mx/index.php/estadisticas/ indicadores-turisticos 28/06/2016

Sneha K.S., Padmapriya B. y Rajeswari T. (2012). Isolation and screening of biosurfactants produced by Pseudomonas aeruginosa from oil spilled soils. Int. j. pharm. biol. sci. arch. 3, 321-325.
Van Hamme J. y Ward O. (2001). Physical and metabolic interactions of Pseudomonas sp. strain JA5-B45 and Rhodococcus sp. strain F9-D79 grown on crude oil and effect of a chemical surfactant on them. Appl. Environ. Microbiol. 67, 4874-4879.

DOI: 10.1128/AEM.67.10.4874-4879.2001

Velasco-Álvarez N. (2011). Alteración en el metabolismo de Aspergillus niger expuesto a una corriente eléctrica, durante la degradación de hexadecano. Tesis Doctoral. Universidad Autónoma Metropolitana - Iztapalapa. Ciudad de México, México, 111 pp.

Volke-Sepúlveda T., Gutiérrez-Rojas M. y Favela-Torres E. (2006). Biodegradation of hexadecane in liquid and solid-state fermentations by Aspergillus niger in a solid-state system: Kinitechigh. Bioresour. Technol. 97, 1583-1591. DOI: 10.1016/j.biortech.2005.07.026

Zwietering M. H., De Kroos J. T., Hasenack B. E., De Wit J. C. y Riet Van T. (1991). Modeling of bacterial growth as a function of temperature. Appl. Environ. Microbiol. 57, 1094-1101. 